\title{
PENGARUH DIGITAL PARENTING TERHADAP SOSIAL KEMANDIRIAN ANAK PRASEKOLAH
}

\author{
1)Faridah Hariyani \\ 1) Jurusan Kebidanan, Poltekkes Kemenkes Kaltim, Jl. MT. Haryono Graha Indah No. \\ 49 Balikpapan \\ E-mail : faridahhariyani@gmail.com
}

\begin{abstract}
Internet users in Indonesia are quite large at around 25 million people. Children are very vulnerable in internet abuse. According to WHO 5-25\% of preschool age children suffer from developmental disorders such as motor delays, language, and social behavior. The purpose of this study was to determine the effect of digital parenting on the social independence of children aged 4-6 years. This type of research is quasiexperimental with one group pretest-posttest design. The number of samples is 40 people. The research measuring instrument uses KPSP with a ratio measurement scale. The results of the study showed an increase in children's social independence scores before and after the digital parenting intervention. After the social intervention the child's independence rises 0.63 points. Before the intervention was given digital parenting the social value of children's independence was 8.65 but after being given the intervention it became 9.28. Based on the results of the Wilcoxon Signed Rank Test, there is the influence of digital parenting on social independence of children aged $4-6$ years p value $=0.004<0.05$. $4-6$ years in PAUD and TK Aisyi.
\end{abstract}

Keywords: digital, parenting, social independence, children

\begin{abstract}
Abstrak
Pengguna internet di Indonesia pada anak-anak cukup besar sekitar 25 juta jiwa. Anak-anak sangat rentan dalam penyalahgunaan internet. Menurut WHO 5-25\% dari anak-anak usia prasekolah menderita gangguan perkembangan seperti keterlambatan motorik, bahasa, dan perilaku sosial. Tujuan penelitian adalah untuk mengetahui pengaruh digital parenting terhadap sosial kemandirian anak usia $4-6$ tahun. Jenis penelitian quasi eksperimen dengan desain one group pretest-posttest design.. Jumlah sampel sebanyak 40 orang. Alat ukur penelitian menggunakan KPSP dengan skala ukur rasio. Hasil penelitian terdapat peningkatan skor sosial kemandirian anak sebelum dan sesudah intervensi digital parenting. Sesudah intervensi sosial kemandirian anak naik 0.63 poin. Sebelum diberikan intervensi digital parenting nilai sosial kemandirian anak 8.65 namun setelah diberikan intervensi menjadi 9.28. Berdasarkan hasil uji Wilcoxon Signed Rank Test terdapat pengaruh digital parenting terhadap sosial kemandirian anak usia 4-6 tahun nilai $\mathrm{p}=0.004<0.05$. Simpulan penelitian terdapat peningkatan sosial kemandirian anak sebelum dan sesudah diberikan digital parenting serta terdapat pengaruh digital parenting terhadap sosial kemandirian anak usia $4-6$ tahun di PAUD dan TK Aisyi.
\end{abstract}

Kata kunci: digital, parenting, sosial kemandirian, anak

\section{PENDAHULUAN}

Indonesia termasuk negara yang jumlah pengguna internetnya sangat banyak, menurut asosiasi penyelenggara jasa internet Indonesia survei pada April 2016 dari 133 juta jiwa pengguna internet terbanyak adalah pada rentang usia 35 sampai 44 tahun yaitusekitar 39 juta jiwa. Pada anak-anak menempati urutan ke tiga yaitu sekitar 25 juta jiwa, sisanya pengguna internetpada usia 25 sampai 34 tahun dan 55 tahun ke atas. Artinyanya sebagian besar manusia telah melakukan aktivitas melalui 
internet tanpa memandang rentang usia (Azizah, 2017)

Orang tua yang lahir antara tahun 1960 sampai 1980 kitakenal dengan generasi X. Generasi ini adalah generasi yang belum mengenali internet sehingga aktivitas mereka dilakukan secara mandiri tanpa ada bantuaninternet. Generasi yang lahir di atas tahun 1980 hingga 1990 dikenal dengan generasi Y.Pada generasi inilah perkembangan teknologi seperti internet dan gawai (gadget) muncul sehingga generasi ini lebih inovatif dan berpikiran terbuka dibandingkandengan generasi $\mathrm{X}$. Setelah generasi Y, kita kenal lagi generasi Z. Generasi inilahir di akhir tahun 90-an, dimana terjadi ledakan inovasi teknologi di berbagai bidang dengan akses yang semakin mudah dan murah (Herlina, 2018)

Hampir semua generasi $\mathrm{Z}$ telah melakukan aktivitas melalui internet. Generasi Zinilah yang biasa dikenal dengan istilah digital native. Digital native adalah gambaranbagi seseorang (terutama anak hingga remaja) yang sejak kelahirannya telahterpapar gencarnya perkembangan teknologi seperti perkembangan komputer, internet, animasi, dan sebagainya yang terkait dengan teknologi.
Hal inilah yangmenyebabkan karakter serta kebiasaan digital native cenderung berbeda dengan generasi sebelumnya. Mereka cenderung memiliki wawasan, pengetahuan,serta pikiran yang sangat terbuka terhadap perkembangan teknologi, cepatmenangkap berbagai informasi, dan dapat beradaptasi dalam situasi apapun (Azizah, 2017)

Di era digital ini, orang tua memiliki tantangan yang besar dalam mengasuh anak-anaknya, seperti yang kita tahu pengguna internet tidak memandang usiadari anak hingga orang dewasa.Banyak orangtua di era digital merasa sulit menemukan cara terbaik mengasuh anak. Disatu sisi penggunaan teknologi digital seperti internet dan video games dalam keluarga tidak bisa terelakkan lagi namun disisi lain anakanak dan orangtua dapat mengalami dampak negatif media itu.Tantangan untuk memaksimalkan potensi anak semakin berat saat kita memasuki era digital (Zulfitria, 2017)

Digital Parenting adalah upaya pengasuhan atau pendidikan yang memperkenalkan dunia digital native kepadapara orangtua, serta mengedukasi mereka agar mampu mempersiapkan anakmenghadapi kencangnya 
perkembangan teknologi. Digital

Parenting melibatkan peran orangtua dalam mendampingi anaknya menghadapi era digitalsehingga ada keahlian yang harus orangtua miliki agar tidak terkecoh dengankecanggihan zaman sekarang. Keahlian tersebut berupa cara berkomunikasi terhadapanak, cara memproteksi gawai anak, cara membuat kesepakatan kepada anak dan sebagainya (Azizah, 2017)

Pada anak-anak usia dibawah 5 tahun diperbolehkan diberi gadget tapi harus diperhatikan durasi pemakaiannya tidak boleh lebih dari 2 jam dan hanya saat senggang. Penggunaan gadget lebih dari 2 jam setiap hari akan mempengaruhi psikologi anak. Era digital menawarkan beragam kesempatan baru untuk mengembangkan diri, namun juga menyimpan ancaman. Orang tua perlu mengembangkan model pengasuhan yang bertujuan menghindarkan anak dari ancaman dan memaksimalkan potensi digital. Teknologi digital membawa perubahan penting dalam kehidupan manusia, maka orang tua perlu memahami bentuk-bentuk perubahanitu agar dapat memandu anaknya (Herlina, 2018).
World Health Organization (WHO) melaporkan bahwa 5-25\% dari anakanak usia prasekolah menderita gangguan perkembangan. Berbagai masalah perkembangan anak, seperti keterlambatan motorik, bahasa, dan perilaku sosial dalam beberapa tahun terakhir semakin meningkat. Anakanaksangat rentan dalam penyalahgunaan internet. Para orang tua memiliki peran yang sangat besar dalam pengawasan terhadap penggunaan internet pada anak. Hal penting yang dapat dilakukan oleh orang tua adalah dengan menerapkan pola asuh yang tepat pada anak di era digital ini (Nahriyah, 2017)

Hasil studi pendahuluan di PAUD dan TK Aisyi pihak guru dan orangtua menyampaikan anak mereka sering menggunakan HP dan laptop untuk bermain dan menonton youtube. Hasil pemeriksaan perkembangan pada tahun 2018 terdapat 6 anak dengan perkembangan tidak sesuai dengan usia anak.

\section{METODE PENELITIAN}

Penelitian ini berjenis quasi eksperimen yaitu penelitian untuk menguji sebab akibat dengan cara mengadakan perlakukan terhadap suatu variabel. 
Desain penelitian yang dipergunakan adalah one group pretest - post test design yaitu penelitian dilakukan sebelum dan sesudah diberi perlakuan. Populasi penelitian adalah seluruh orangtua dan anak di PAUD dan TK Aisyi Balikpapan dipilih dengan teknik purposive sampling. Jumlah sampel 40 orang.

\section{HASIL PENELITIAN}

Tabel 1. Karakteristik Subjek Penelitian berdasarkan Usia dan Pendidikan

\begin{tabular}{lcc}
\hline \multicolumn{1}{c}{ Karakteristik } & Jumlah & $\%$ \\
\hline Usia Anak & & \\
$48-59$ bulan & 33 & 17.5 \\
$60-72$ bulan & & 82.5 \\
& & \\
Usia Ibu & 0 & 0 \\
$<20$ tahun & 33 & 82 \\
$20-40$ tahun & 7 & 18 \\
$>40$ tahun & & \\
& & 38 \\
Pendidikan & 15 & 40 \\
Dasar (SD/SMP) & 16 & 22 \\
Menengah (SMA/SMK) & 9 & \\
Tinggi (Diploma/Sarjana) & & \\
\hline
\end{tabular}

Berdasarkan Tabel 4.1 sebagian besar anak berusia $60-72$ bulan $(82.5 \%)$, sebagian besar ibu berusia $20-40$ ( $82 \%$ ) tahun dengan pendidikan tingkat menengah (40\%).

Tabel 2. Perkembangan Anak Sebelum dan Sesudah Digital Parenting di PAUD dan TK Aisyi Balikpapan

\begin{tabular}{lcccc}
\hline \multicolumn{1}{c}{ Variabel } & Mean & Median & SD & Min-Max \\
\hline $\begin{array}{l}\text { Sebelum Intervensi digital } \\
\text { parenting }\end{array}$ & & & & \\
$\begin{array}{l}\text { Perkembangan } \\
\text { Sesudah Intervensi digital } \\
\text { parenting }\end{array}$ & 8.65 & 9 & 1.562 & $4-10$ \\
\begin{tabular}{l} 
Perkembangan \\
\hline
\end{tabular} & 9.28 & 10 & 1.339 & $4-10$ \\
\hline
\end{tabular}


Berdasarkan Tabel 4.2 terlihat digital parenting. Sesudah intervensi peningkatan skor sosial kemandirian rerata sosial kemandirian anak naik 0.63 anak sebelum dan sesudah intervensi poin.

Tabel 3. Tabel analisis bivariat pengaruh digital parenting terhadap sosial kemandirian anak usia 4-6 tahun

\begin{tabular}{cccc}
\hline Variabel & N & Mean Rank & P-Value \\
\hline Post test-pre test : Perkembangan & 40 & 10.97 & 0.004
\end{tabular}

Ket: diuji dengan wilcoxon signed rank test

Berdasarkan hasil uji Wilcoxon Signed Rank Test terdapat pengaruh digital parenting terhadap sosial kemandirian

\section{PEMBAHASAN}

Pada karakteristik responden sebagian besar anak berusia $60-72$ bulan, sebagian besar ibu berusia 20-40 tahun dengan pendidikan tingkat menengah. Semakin cukup umur individu, tingkat kematangan dan kekuatan seseorang akan lebih matang dalam berpikir dan bekerja. Pendidikan ibu merupakan salah satu faktor yang sangat penting karena semakin tinggi pendidikan seseorang, semakin tinggi pula dalam hal pengetahuan, sikap, dan praktik.

Pada penelitian ini, setelah orangtua diberikan pelatihan digital parenting kemudian dilakukan pemantauan penggunaan gawai anak dirumah selama 3 minggu meliputi anak usia 4-6 tahun nilai $\mathrm{p}=0.004<$ 0.05

pemantauan lama penggunaan gawai maksimal 20 menit/hari, menyeleksi konten/informasi dari internet sebelum ditonton oleh anak, penggunaan gawai sesuai dengan usia dan perkembangan anak, memantau posisi anak saat menggunakan gawai posisi harus sejajar, tidak membungkuk, ditempat terang, memberikan konten/informasi untuk menstimulus perkembangan anak, memproteksi gawai yang digunakan oleh anak, orangtua menyediakan aktivitas pengganti yang disenangi anak selain menonton atau bermain gawai, anak lebih diarahkan untuk bermain didunia nyata dibanding bermain games di HP serta orangtua membatasi penggunaan HP (Role Model). 
Terdapat peningkatan skor perkembangan anak sebelum dan sesudah intervensi digital parenting. Sesudah intervensi rerata perkembangan anak naik 0.63 poin. Sebelum diberikan intervensi digital parenting nilai perkembangan 8.65 yaitu dalam kategori perkembangan anak meragukan, namun setelah diberikan intervensi menjadi 9.28 dalam kategori perkembangan sesuai dengan usia anak. Berdasarkan hasil uji Wilcoxon Signed Rank Test terdapat pengaruh digital parenting terhadap sosial kemandirian anak usia 4-6 tahun nilai $\mathrm{p}=0.004<$ 0.05 .

Perkembangan anak adalah bertambahnya struktur dan fungsi tubuh yang lebih kompleks dalam kemampuan gerak kasar, gerak halus, bicara dan bahasa serta sosialisasi dan kemandirian.

Sosialisasi dan kemandirian adalah aspek yang berhubungan dengan kemampuan mandiri anak (makan sendiri, membereskan mainan selesai bermain), berpisah dengan ibu/pengasuh anak, bersosialisasi dan berinteraksi dengan lingkungannya, dan sebagainya (Kemenkes, 2016).

Salah satu faktor yang mempengaruhi perkembangan anak salah satunya adalah pengasuhan (parenting) yaitu upaya pendidikan yang dilaksanakan oleh orangtua dalam mendukung perkembangan fisik, emosional, sosial dan intelektual meliputi aktivitas memberi petunjuk (guiding) dan melindungi (protecting) pada anak ketika mereka tumbuh dan berkembang (Kemendikbud, 2016).

Pada era digital orang tua memiliki tantangan yang besar dalam mengasuh anak, pengguna internet tidak memandang usia dari anak hingga orang dewasa, banyak orangtua di era digital merasa sulit menemukan cara terbaik mengasuh anak. Disatu sisi penggunaan teknologi digital seperti internet dan video games dalam keluarga tidak bisa terelakkan lagi namun disisi lain anakanak dan orangtua dapat mengalami dampak negatif dari media tersebut. Tantangan untuk memaksimalkan potensi anak semakin berat saat kita memasuki era digital (Zulfitria, 2017)

Digital parenting adalah upaya pengasuhan atau pendidikan yang memperkenalkan dunia digital native kepada para orangtua, serta mengedukasi mereka agar mampu mempersiapkan anak menghadapi lajunya perkembangan teknologi. Digital parenting melibatkan peran 
orangtua dalam mendampingi anak menghadapi era digital sehingga ada keahlian yang harus dimiliki orangtua agar siap menghadapi kecanggihan teknologi. Keahlian tersebut berupa cara berkomunikasi terhadap anak, cara memproteksi gawai anak, cara membuat kesepakatan kepada anak dan sebagainya (Azizah, 2017)

Anak-anak membutuhkan bimbingan dan arahan dari orang tua untuk menggunakan media digital dengan bijaksana. Orang tua perlu memahami nilai utama dunia digital yaitu kreativitas, kolaborasi dan berpikir kritis. Orangtua diharapkan mampu melindungi anak dari ancaman era digital, tetapi tidak menghalangi potensi manfaat yang bisa ditawarkannya. Orangtua dapat mengimbangi paparan media digital dengan mengenalkan pengalaman dunia nyata seperti aktivitas kesenian, kegiatan luar ruangan, olahraga, membaca interaktif, musik dan gerakan, permainan tradisional dan sebagainya kepada anak (Kemendikbud, 2017)

Jika anak sudah terpapar perangkat digital, lebih baik untuk mengarahkan dengan komunikasi efektif untuk memutuskan berapa lama dan kapan mereka dapat menggunakannya.
Sepakati waktu penggunaan dan waktu untuk berhenti memanfaatkan perangkat media digital di malam hari (Kemendikbud, 2017).

Hasil penelitian menunjukan kebanyakan gadget yang diberikan para orang tua kepada anaknya berdasarkan keinginan anak untuk tujuan tertentu seperti untuk mengenalkan teknologi lebih dini atau sekedar untuk membuat anaknya tidak bosan. Terkadang gadget dijadikan para orang tua untuk mengalihkan anak-anak agar tidak mengganggu pekerjaan orang tuanya sehingga para orang tua menyediakan fasilitas berupa gadget untuk anaknya yang masih berusia dini (Nurrachmawati, 2014).

Ketergantungan terhadap gadget pada anak disebabkan karena lamanya durasi dalam menggunakan gadget. Bermain gadget dengan durasi yang cukup panjang dan dilakukan setiap hari, bisa membuat anak berkembang ke arah pribadi yang antisosial. Dampak yang ditimbulkan dari hal itu adalah dapat membuat anak lebih bersikap individualis karena menyebabkan lupa berkomunikasi dan berinteraksi terhadap lingkungan di sekitarnya (Maulida, 2013). Usia dini merupakan usia anak dapat mengasah kemampuan 
bersosialisasinya dengan baik

dilingkungan sosial.

Hasil penelitian penggunaan gadget pada anak usia dini lebih menyenangkan dibandingkan bermain dengan teman sebayanya. Hal ini karena berbagai aplikasi permainan yang terdapat pada gadget lebih menarik perhatian anak dibandingkan dengan permainan yang terdapat di lingkungan sekitarnya. Secara tidak sadar anak anak sudah mengalami ketergantungan menggunakan gadget. Ketergantungan inilah yang menjadi salah satu dampak negatif yang sangat berpengaruh dengan perkembangan sosial dan kemandirian anak (Pebriana, 2017)

Orang tua perlu mendampingi dan membimbing anaknya saat sedang menggunakan gadget, dan peran orang tua dalam mendisiplinkan anak sangat dibutuhkan agar anak tidak mengalami ketergantungan yang akan menyebabkan dampak negatif terhadap perkembangan terutama hubungannya dengan perkembangan sosial anak. Peran orang tua dalam pendampingan dialogis anak pada penggunaan gadget adalah mengontrol apa saja yang dilakukan dan dilihat anak supaya mencegah anak dari pengaruh negatif pemakaian gadget (Waisyah, 2015)

Beberapa prinsip umum pengasuhan digital meliputi norma, dampak teknologi, dampak pesan, masalah sensitif dan contoh perilaku. Orang tua harus memberikan contoh perilaku bermedia digital yang baik pada anak. Jika ingin anak bijaksana menggunakan media digital, orang tua harus memberikan suri tauladan. Tentukan waktunya bermedia digital yang tidak menganggu aktivitas penting seperti makan, istirahat, belajar, bermain, beribadah, interaksi keluarga. Orang tua juga harus membiasakan diri hanya mengakses informasi yang penting dan bermanfaat, tunjukan pada anak mengenai kebiasaan tersebut serta diskusikan dengan anak masalahmasalah buruk yang diakibatkan media digital sesuai usia mereka. Berdasarkan prinsip tersebut, orang tua perlu mengembangkan pola pengasuhan yang melindungi sekaligus mengatur akses anak terhadap media digital. Perlindungan teknis dan pengawasan saja tidak cukup, orang tua perlu membicarakan tentang keamanan dan pengendalian diri, mendiskusikan perilaku bermedia digital dan mendorong keingintahuan untuk hal positif. Kembangkan pengasuhan digital sesuai dengan fase pertumbuhan dan 
perkembangan anak. Banyak manfaat yang bisa diperoleh dari kecanggihan teknologi. Melalui gadget dan internet, proses belajar anak menjadi lebih kreatif dan menyenangkan. Jika anak memiliki bakat menari atau menggambar memutar video tutorial di youtube bisa ditiru dan menjadi inspirasi bagi anak (Kemendikbud, 2017)

Bahaya penggunaan gawai yang tidak sesuai usia anak antara lain 1) Dapat Mengganggu pertumbuhan otak anak, karena stimulasi berlebih dari gawai menyebabkan keterlambatan kognitif, gangguan dalam proses belajar, tantrum, meningkatkan sifat impulsif, menurunkan anak untuk mandiri. 2) Tumbuh kembang lambat karena membatasi gerak fisik. 3) Menunda perkembangan bahasa. 4) Risiko obesitas yang dapat menyebabkan diabetes, stroke dan jantung pada usia dewasa. 5) Masalah tidur karena dampak melihat layar terlalu lama dan dampak dari isi media digital. 6) Kesulitan konsentrasi dan perilaku aktif. 7) Perkembangan sosial terganggu, tumbuh jadi pribadi yang mementingkan diri sendiri sehingga sulit bergaul secara langsung. 8) Penggunaan gawai yang berlebihan di usia dini bisa menganggu perkembangan ketrampilan berempat, sosial dan pemecahan masalah yang biasanya diperoleh anak dengan menjelajah, bermain dan berinteraksi dengan teman sebaya (Kim, 2013)

Menurut pakar psikologi yang dibutuhkan anak-anak ketika mereka tumbuh adalah kehadiran orangtua untuk senantiasa mendampingi serta memonitor apa yang mereka lakukan. Pada era digital dibutuhkan komunikasi dua arah artinya orangtua tidak hanya sekedar melarang atau memberi instruksi kepada anak saja, tetapi juga bersikap sebagai pendengar yang baik dan memberi solusi permasalahan yang dihadapi anak. Komunikasikan secara terbuka hal-hal apa saja yang belum pantas dilakukan atau dilihat anak, misalnya menjelaskan mengapa orangtua melarang anak menonton video atau tayangan dengan konten orang dewasa. Jelaskan pula aturan yang bijak dalam menggunakan gadget. Komunikasi terbuka antara orangtua dan anak terbukti efektif mengantisipasi anak dari pengaruh negatif pemakaian gadget (Rahman, 2017 )

$\begin{array}{llr}\text { Orangtua } & \text { perlu } & \text { menambah } \\ \text { pengetahuan } & \text { saat } & \text { melakukan } \\ \text { pendampingan pada } & \text { generasi digital, } \\ \text { orangtua perlu meluangkan waktu untuk }\end{array}$


melihat situs yang pernah dikunjungi anak. Orangtua perlu mengarahkan penggunaan perangkat dan media digital dengan jelas. Jika anak sudah terpapar perangkat digital, lebih baik untuk mengarahkan dengan komunikasi efektif untuk memutuskan berapa lama dan kapan mereka dapat menggunakannya. Sepakati waktu penggunaan dan waktu untuk berhenti memanfaatkan perangkat media digital dimalam hari. Imbangi waktu menggunakan media digital dengan interaksi di dunia nyata, orangtua dapat mengimbangi paparan media digital dengan mengenalkan pengalaman dunia nyata seperti aktivitas kesenian, musik dan gerakan, permainan tradisional dan sebagainya kepada anak (Kemendikbud, 2016)

Pinjamkan anak perangkat digital sesuai keperluan dan pilihkan program/aplikasi positif. Orangtua perlu mengidentifikasi program/aplikasi yang memiliki edukasi dan memberikan dampak positif bagi perkembangan anak. Orangtua perlu mendampingi dan berinteraksi dengan anak selama penggunaan media digital. Orangtua perlu bijaksana menggunakan perangkat digital selama berinteraksi dengan anak dan tidak menggunakan perangkat digital sebelum tidur Telusuri aktivitas anak didunia maya, orangtua dapat memonitor situs web yang pernah dikunjungi dan pastikan anak tidak mengunjungi situs yang tidak sesuai (Herlina, 2018)

Saat ini telah terdapat program piranti lunak (web filtering) yang dapat membantu orangtua dalam melakukan scan ataupun memblok alamat website yang mengandung fitur yang tidak sesuai dengan perkembangan anak salah satunya adalah dengan parental control. Fitur ini memungkinkan orang tua membatasi akses konten yang dirasa tidak cocok bagi anak. Fungsi parental control sebagai filter konten yaitu membatasi konten yang bisa dikonsumsi anak-anak dan sebagai kontrol penggunaan yaitu membatasi kapan perangkat bisa digunakan dan seberapa banyak layanan data yang bisa digunakan serta sebagai monitoring yaitu mengikuti dan melacak lokasi serta aktivitas anak saat menggunakan gawai (Herlina, 2018)

Menyeleksi konten yang sesuai untuk anak dapat dilakukan dengan piranti lunak dan pemahaman. Orang tua dapat menggunakan kategorisasi atau rating yang digunakan penyedia konten. Rating aplikasi permainan di 
telepon seluler berbasis android terdapat indikator usia yang diperbolehkan untuk menggunakan aplikasi dan ini harus diketahui oleh orangtua. Biasanya indikator tersebut tertulis dibawah judul aplikasi ketika kita memilih aplikasi tersebut di play store. Aplikasi yang aman untuk anak usia 4-6 tahun adalah aplikasi dengan rating $3+$ atau 4+ (Fahrizal, 2018)

Beberapa aplikasi pada play store memiliki kategori khusus keluarga yang berisi konten-konten ramah anak. Aplikasi lain seperti youtube juga menyediakan saluran youtube kids, pastikan anak-anak hanya menonton dari saluran yang aman. Tapi pengaturan semacam itu tidak cukup, karena nilai masing-masing keluarga berbeda, maka orang tua perlu menekankan batasan kewajaran konten terkait dengan penampilan tubuh, adegan kekerasan, nilai cerita dan sebagainya. Orangtua perlu memahami informasi yang disediakan media. Pemahaman dilakukan dengan menggunakan kerangka moral dan rasional masing-masing keluarga (Fahrizal, 2018)

Kunci utama pengasuhan digital adalah adanya kesepakatan antara ibu dan ayah mengenai cara pengasuhan anak yang paling sesuai dengan nilainilai yang mereka anut. Terapkan cara pengasuhan itu secara konsisten melalui interaksi langsung, suri tauladan, dan kebiasaan dalam keluarga. Sikapi penggunaan media digital di tengah keluarga secara bijaksana. Buatlah aturan dan kesepakatan dalam keluarga terkait penggunaan media digital itu. Pastikan seluruh keluarga mendapatkan lebih banyak manfaat daripada efek negatifnya (Kemendikbud, 2017)

\section{UCAPAN TERIMAKASIH}

Ucapan terimakasih kepada Direktur Poltekkes Kemenkes Kaltim, Ka.Unit Litbang, Ketua Jurusan Kebidanan dan Pimpinan PAUD dan TK Aisyi yang telah memberikan bantuan dan kerjasama yang baik dalam penelitian ini. Penelitian ini dibiayai oleh anggaran DIPA Poltekkes Kaltim tahun 2019 untuk Skema Penelitian Unggulan Terapan dengan Nomor SK: PP.03.01/1.1/4734/2019 Tanggal 27 Mei 2019

\section{DAFTAR PUSTAKA}

Azizah, Ocktaviane, Susanti \& Putri. (2017). Modul pelatihan parenting diera digital. Jakarta: Deputi Bidang Perlindungan Anak. 
Dahlan S. (2010). Besar sampel dan cara pengambilan sampel dalam penelitian kedokteran dan kesehatan. Edisi ke-3. Jakarta: Salemba Medika.

Fahrizal A.(2018). Smartdigiparents tips dan trik gadget dan dunia online untuk para orangtua di era digital.Yogyakarta: Diandra Kreatif.

Herlina, Setiawan \& Jiwana. (2018). Digital Parenting: Mendidik anak di era Digital. Yogyakarta. Samudra Biru

Ismaniar, Sunarti. (2018). Buku Ajar Pelatihan Parenting. Padang. Jurusan Pendidikan Luar Sekolah Universitas Negeri Padang.

Ismael S, Sastroasmoro S. (2011). Dasar-dasar metodologi penelitian klinis. Edisi ke-4. Jakarta: Sagung Seto

Kemendikbud. (2016). Seri Pendidikan Orangtua: Pengasuhan positif. Jakarta. Kementerian Pendidikan dan Kebudayaan.

Kemendikbud. (2017). Buku Saku Mendidik Anak Di Era Digital. Jakarta. Kementerian Pendidikan dan Kebudayaan.

Kemenkes. (2016). Pedoman Pelaksanaan: Stimulasi, Deteksi dan Intervensi Dini Tumbuh Kembang Anak Ditingkat Pelayanan Dasar. Jakarta. Kementerian Kesehatan.
Kim,YB.(2013). Young children in digital age. University of Nevada Cooperation Extension

Livingstone S, Mascheroni G, Dreier M, Chaudron S and Lagae K.(2015). How parents of young children manage digital devices at home the role of income, education and parental style. London: EU Kids Online.LSE

Maulida, Hidayahti (2013). Menelisik Pengaruh Penggunaan Aplikasi Gadget Terhadap Perkembangan Psikologis Anak Usia Dini. Jurnal Ilmiah Teknologi Pendidikan. Semarang: FKIP Universitas Negeri Semarang. 8-12

Nahriyah S.( 2017).Tumbuh Kembang anak di Era Digital. Jurnal Pendidikan dan Studi Islam. 65-74.

Nurrachmawati (2014). Pengaruh sistem operasi mobile android pada anak usia dini. Jurnal FT Universitas Hasanuddin. 12-18

Pebriana P. (2017). Analisis penggunaan gadget terhadap kemampuan interaksi sosial pada anak usia dini. Jurnal Obsesi: Jurnal pendidikan anak usia dini.1(1), 1-11

Rahman A. (2017). Panduan mendidik anak di era digital. Bandung: Beranda Agency.

Satari MH, Wirakusumah FF. (2011). Konsistensi penelitian dalam bidang kesehatan. Bandung: PT Refika Aditama. 
Suryanto, Purwandari H, Mulyono WA.

Dukungan keluarga dan sosial

dalam pertumbuhan dan perkembangan personal sosial, bahasa dan motorik pada balita di kabupaten Banyumas. Jurnal kesehatan masyarakat.103-109

Waisyah Y. (2015). Prosiding seminar nasional pendidikan inovasi pendidikan untuk pendidikan berkemajuan: Pentingnya pendampingan dialogis orangtua dalam penggunaan gadget pada anak usia dini. Yogyakarta.

Zulfitria. (2017). Pola Asuh Orang Tua Dalam Penggunaan Smartphone pada anak sekolah dasar. Jurnal Ilmiah PGSD Holistika. 95-102 